\title{
The quintessence of colour enhancement in ornamental fishes: an empirical pathway towards rainbow revolution
}

\author{
Paramita Banerjee Sawant $^{1, *}$, Srijit Chakravarty ${ }^{1}$, Subrata Dasgupta ${ }^{1}$, \\ Narinder Kumar Chadha ${ }^{1}$ and Bhawesh T. Sawant ${ }^{2}$ \\ ${ }^{1}$ ICAR-Central Institute of Fisheries Education Versova, Mumbai 400 061, India \\ ${ }^{2}$ Taraporevala Marine Biological Research Station (Dr Balasaheb Sawant Konkan Krishi Vidyapeeth), Mumbai 400051 , India
}

\begin{abstract}
One of the greatest challenges in the ornamental fish industry is to replicate accurate natural colour of fishes in captivity. Numerous attempts to preserve colour in captivity have been ineffective in reducing its fading, making it an important determinant in the selection of ornamental fish species for trade in terms of saturation, brightness and hue. Colour development of ornamental fishes has been widely studied, yielding curious insights about evolutionary genetics and having a discerning role, either as deceptive or attractive (aposematic) signals in mating as well as in camouflaging (Delphic) patterns during predator-prey interactions. This article discusses colour enhancement strategies with reference to nutritional interventions through carotenoid-rich feed ingredients, genetic manipulation or injection of colour in subcutaneous layers of the skin. An insight into the mechanism of pigmentation shows that motility and pigment dispersion of chromatophores are the two drivers by which fishes control integumentary colour variation. Research on colour development and its enhancement has witnessed novel techniques to support the ornamental fish industry. Therefore, this article also sheds light to answer questions on various issues pertaining to environmental and physiological effects on colouration. It attempts to provide insight on potential research areas, with caution on ethical and legal issues to ensure sustainability, so as to restrict risks of unwanted inheritance of colour patterns. It also highlights the problems of identity crisis among conspecifics thereby bringing a 'rainbow revolution' to the ornamental industry.
\end{abstract}

Keywords: Colour enhancement, chromatophore, ornamental fish, rainbow revolution.

COLOURATION is the general appearance of an animal resulting from the reflection or emission of light from its skin surface. Vibrant colours in different shapes and forms in ornamental fishes make their rearing a favourite hobby, which has a rich history that flourished with major

\footnotetext{
*For correspondence. (e-mail: aquaparo@gmail.com)
}

advancements in civil aviation after the Second World War, when ornamental fishes started to be exported globally to the developed countries ${ }^{1}$. Although the global ornamental fish trade is punitive compared to the edible fish industry, it is growing at an enviable rate of $14 \%$ annually with an annual corpus of US\$ 200-300 million ${ }^{2}$. Global aquarium trade is mostly dependent on wild catches. In addition to freshwater ornamental fishes, 1471 species of marine finfish, 140 species of corals and more than 500 species of marine invertebrates are traded globally adorning 1.5-2 billion marine aquaria, more than 600,000 in USA alone, making it a second most popular hobby in the world after photography ${ }^{3}$. Illegal trade of native ornamental organisms raises concern on their sustainability (being detrimental to the local flora and fauna), and this is further aggravated by climate change $e^{4,5}$.

Fishes exhibit a variety of beautiful colours and colour patterns like the rainbow, from violet to red, tints and shades of green, bright yellows, subdued yellows, oranges, vibrant reds and all colours between blue and red. This diversity in colour patterns appropriately gives rise to the word 'ornamental', also forming a basis for their descriptive names such as blue damsel, yellow cichlid, orange chromide, etc. Although fishes inherit skin colour, they are unable to produce red, orange, yellow, green and some blue pigments, which must be obtained from the food they consume. A number of colour enhancement strategies are presently in vogue, but only a few have been documented. Besides conventional strategies such as nutritional supplementation of carotenoids and genetic manipulations colour enhancement strategies can be as gruesome as injecting toxic dyes into nearly colourless fishes such as Indian glassfish (Chanda ranga), to add glitter to the trade by unethical means ${ }^{6}$.

In addition to visual pleasure for the onlookers, colour in ornamental fishes provides a conspicuous route to understand the underlying principles of signalling in them in response to variations in environmental factors such as water-quality alterations, genetic manipulations, adaptations, reproductive stimuli, etc. ${ }^{6,7}$. 


\section{The process of colour development}

\section{Chromatophores: origin, arrangement, motility and pigmentation mechanisms}

Variation of colouration and pigmentation patterns in fish is attributed to six different types of chromatophores, viz. melanophores, xanthophores, erythrophores, iridophores, leucophores and cyanophores, in contrast to only one type (melanocytes; secreting eumelanin for black and pheomelanin for yellow/brown colouration) in mammals ${ }^{8,9}$. Chromatophores are mostly derived from the neural crest, except leucophores and cyanophores, and their arrangement patterns vary structurally according to skin location, age and physiological state of the fish ${ }^{10}$. Both melanophores and xanthophores are dendritic cells having innervations from preganglionic nerve fibres originating from the 15 th vertebra of the spinal $\operatorname{cord}^{11}$. Ultrastructure of melanophores (as revealed by electron-microscopic studies), shows them enclosed within a single cell membrane encompassing melanosomes and other cell organelles (Figure 1). Most of the observations favour the view that melanosomes are selectively moved through the cellular processes, leaving the cell contour rather fixed ${ }^{12}$.

The motile activities of the chromatophores are controlled mostly by electrical signals or through adrenergic monoamines and the stimulation of $\alpha$-adrenoceptors by catecholamines. The process is accompanied by an increase in intracellular $\mathrm{Ca}^{2+}$ levels, which in turn trigger the aggregation of melanosomes ${ }^{13}$. Paracrine factors such as endothelins (ETs) are also reported to be involved in these processes ${ }^{14}$. Recent studies on stripe formation in zebrafish reveal existence of a complex interplay between the pigment cells in which iridophores promote and sustain melanophores and attract xanthophores, whereas xanthophores repel melanophores. Stripe formation, though initiated by iridophores appearing at the horizontal myoseptum, gradually becomes a self-organizing autonomous process $^{15}$.

\section{Environmental factors affecting colour development/ colour change in fishes}

Colour change in fish can be broadly categorized into two basic categories: (i) physiological colour change, a comparatively faster process which is evident within seconds (attributed to rapid motile response of the chromatophores), and (ii) morphological colour change, involving the change in morphology and density of chromatophores ${ }^{16}$. This can be further elucidated by the fact that fishes adapted to a darker background have a greater number of melanophores concentrated at the head and dorsal trunk region stimulated by the action of melanocyte stimulating hormone (MSH), secreted from the pars intermidia of the pituitary. In contrast, fishes adapted to a lighter background have higher number of dopa-positive melaoblasts corresponding to the enhanced secretion of melanocyte concentrating hormone $(\mathrm{MCH})$, released from the pars nervosa, favouring effective camouflage mechanisms to evade predation. Such dispersion or contraction of melanophores is controlled through a cAMP-mediated protein kinase A pathway and $\mathrm{Ca}^{2+}$ ions located within the melanophore ${ }^{17,18}$. In an experiment with rainbowfish (Melanotaenia australis), Kelley et al. ${ }^{18}$ showed increase in area and brightness of colour (especially red colouration) when reared in an environment rich in dissolved organic matter. These fishes also moved in lightly packed shoals with a probable explanation that red colouration, being least diffractive, could attribute to conspicuousness of colour patterns leading to better communication between individuals in visually compromised environments. This ability of changing colour may have a suppressive impact on selection also, as the chromatic plasticity evades natural selection methods of elimination through predation or natural mortality ${ }^{19}$.

\section{Strategies for colour enhancement}

Several viable strategies for colour enhancement of ornamental fishes (to earn a competitive edge in the growing market) include dietary supplementation of colour enhancers, genetic manipulations and injecting dyes in the subcutaneous layers of fishes (commonly known as juicing or painting). Nutritional strategies remain the most widely used method of colour enhancement, where fish diets are supplemented with colour enhancers rich in carotenoids (mostly microalgae, plant/animal sources and synthetic derivatives). Figure 2 provides a summary of the inter-relationship between various factors instrumental in bringing out efficient pigmentation in ornamental fish.

\section{Nutritional strategies for colour enhancement}

Carotenoids: structure and function: This may be considered as the most potent route for colour enhancement, owing to the simplicity of the method and eco-friendly nature of such practices. Carotenoids are non-nitrogenous fat-soluble pigments synthesized from geranyl diphosphate (GPP) by all photosynthetic organisms ${ }^{20}$. Photosynthetic plants can synthesize lycopene and $\beta$-carotene and in their biosynthetic pathway, lycopene is converted to $\beta$ carotene, which in turn is further metabolized to astaxanthin, which is a non-plant carotenoid ${ }^{21}$. Dietary carotenoids play an important role in the regulation of skin and muscle colour in fish. Over 750 known natural carotenoids have been described since the structure was first elucidated by Kuhn and Karrer in 1928-1930 (with a basic structure of tetraterpenoids having a carbon backbone of 40 carbon atoms), and are broadly divided into 

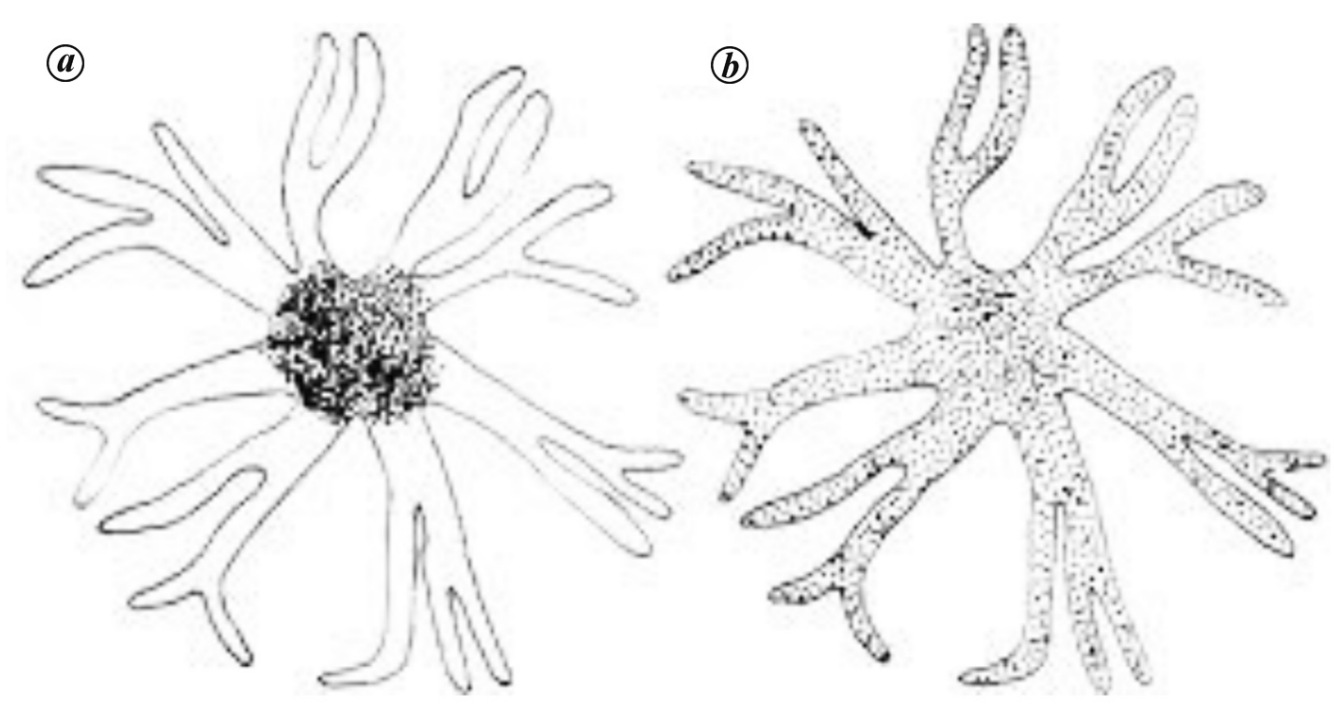

Figure 1. Teleost chromatophore showing (a) aggregated and (b) dispersed state.

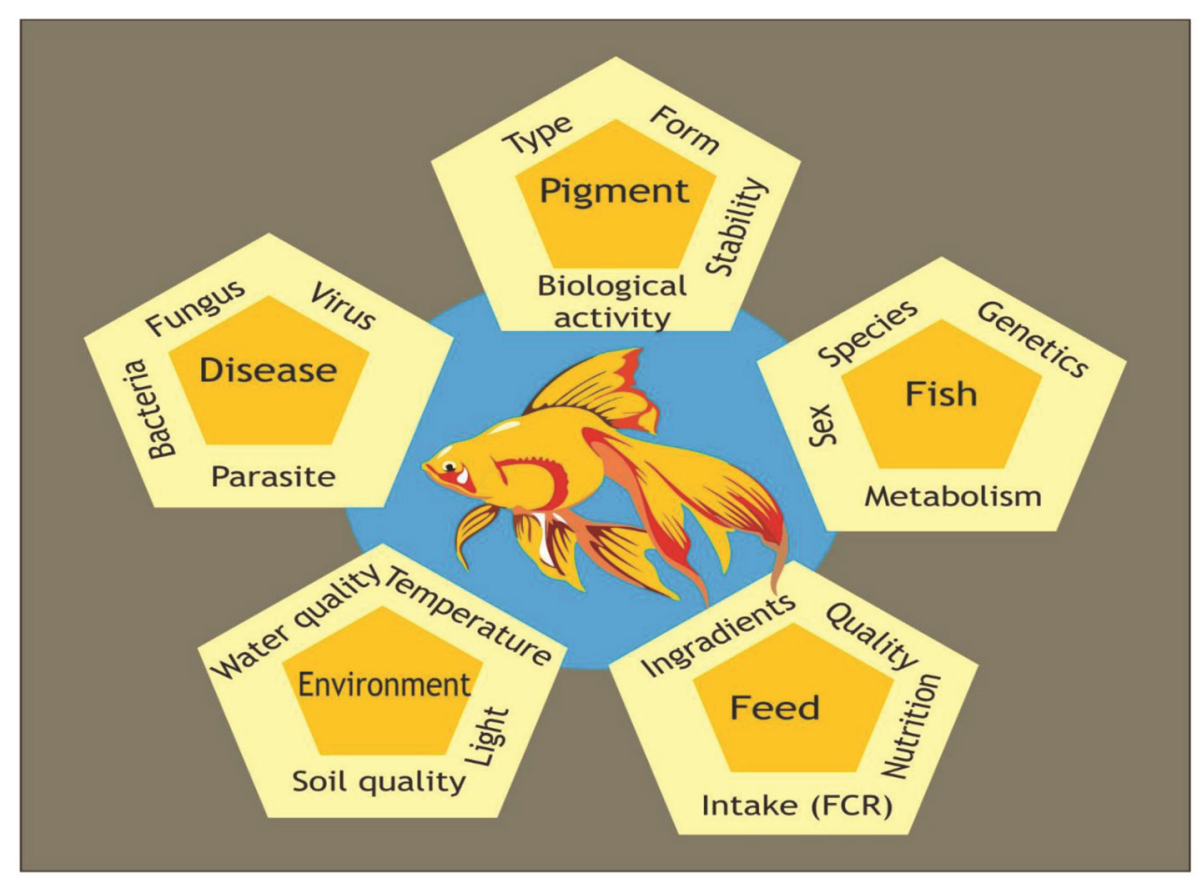

Figure 2. Relationship among various factors bringing out effective pigmentation in fish (modified from Diler and Dilek ${ }^{95}$ ).

carotenes (comprising carbon and hydrogen) and xanthophylls, which are oxygenated derivatives of carotenes ${ }^{22,23}$. They can exist either in free or esterified forms, or in association with protein as keratin as in salmonid eggs, birds and ornamental fishes ${ }^{20.23 .24}$. Fishes, unlike other animals, do not possess the ability to biosynthesize carotenoids de novo, but can modify alimentary carotenoids and store them in the integument and other tissues ${ }^{20}$. Farmed fish feeding on formulated diet has no or little access to carotenoids and therefore, the necessary carotenoids must be added to their diet. For example, astaxanthin supplementation in the diet of cultured snapper,
Pagrus pagrus and goldfish, Carassius auratus led to improvement in redness of their skin, which however, diminished over time in the absence of astaxanthin supplementation $^{25}$.

The effectiveness of carotenoid sources in terms of deposition and pigmentation is species-specific ${ }^{26,27}$. This is usually attributed to the pigment conversion ability of the fishes. For example, goldfish converts the dietary yellow pigment zeaxanthin to a more conspicuous red astaxanthin $^{28}$, while trout, Oncorhynchus mykiss converts astaxanthin to zeaxanthin ${ }^{29}$. The third variety is seen in red sea bream, Pagrus major, which does not convert 


\section{REVIEW ARTICLES}

xanthophylls to either canthaxanthin or astaxanthin ${ }^{30}$. The most effective carotenoids used for the colour enhancement of ornamental fishes are astaxanthin and canthaxanthin, alone or in combination ${ }^{31}$. In addition to colour enhancement, these also function as antioxidants and immunostimulants, triggering interest in research ${ }^{32,33}$. This is in agreement with the carotenoid trade-off hypothesis, according to which animals that display carotenoid-based signals should experience a trade-off when allocating carotenoids between physiological and pigmentation demands ${ }^{34}$. Carotenoid demands for developing immunity and antioxidant protection can reinforce the intensity of carotenoid-based signals leading to enhanced mating success. Females have a greater demand for carotenoids than their male counterparts during the active reproductive phase for allocating carotenoids needed for the formation of yolk protein in their eggs ${ }^{35-39}$.

Application of carotenoids for colour enhancement: Plasticity of skin colouration of ornamental fishes and their susceptibility to dietary manipulations has sparked research interest in this field since the 1970s, starting with the phenomenal work of Tom Lovell and his team using marigold petals as carotenoid supplement in the diet of tiger barb ${ }^{40}$. This paved the way to the search for more potent carotenoid-rich natural ingredients such as spirulina, marine algae, crustacean exoskeleton, etc. with dietary levels varying from $4 \%$ to $20 \%$ in the feed ${ }^{41-44}$, microalgae (Haematococcus, Arthrospira, Dunaliella, Chlorella, Chlorococcum, Leptolyngbyatenuis, Nostocellipsosporum), cyanobacteria containing high amounts of pigments $(\sim 3-5 \% \text { of biomass })^{45}$ as well as several macroalgae such as Porphyra, Gracillaria and Palmaria ${ }^{46,47}$.

During the course of time, research interest inclined towards finding alternatives or rather unconventional ingredient sources such as yeast (Rhodotorula sanneii), chesnut flowers $^{48}$, paprika and red pepper (Capsicum annum $)^{49}$, carrot (Daucus carota) ${ }^{50}$, marigold petal (Tagetes erecta $)^{40}$, China rose petal (Hibiscus rosasinensis) ${ }^{51}$, rose petals (Rosa chinensis) ${ }^{52}$, Ixora coccinea, Crossandra infundibuliformiss $^{53}$, apple peel meal ${ }^{54}$ and oleoresin obtained from marigold flowers ${ }^{55}$. Marigold petals are also a rich natural source of lutein, beta carotene and xanthophyll in esterified forms of palmitic and myristic acids ${ }^{56}$. Crustacean wastes like shrimp head and crab offal also yield considerable amounts of carotenoids and astaxanthin, and are thereby finding increasing use in fish feed for colour enhancement as also the pharmaceutical industry ${ }^{57}$. While immediate effects of carotenoid (as an antioxidant) appear positive, a potentially negative effect of its high doses could lead to high plasma creatine kinase, indicative of increased breakdown of skeletal muscle ${ }^{58}$. Therefore, carotenoproteins (carotenoids with protein complexes) having enhanced digestibility and stability (than carotenoids) may be used in low doses to express beautiful colours, different from the pigment itself $f^{59}$.
Carotenoproteins from shrimp shell waste have been researched as the most potent in fish diets owing to their superior 2,2-diphenyl 1-picryl hydrazyl radical scavenging activity, ferric reducing antioxidant power assay and 2,2-azinobis (3-ethylbenzothiazoline-6-sulphonic acid) diammonium salt radical scavenging activity ${ }^{60}$. Again, free forms of carotenoids have been argued to be better utilized by fishes ${ }^{61}$. This paved the way for use of synthetic astaxanthin in fish feed for colour enhancement, especially in ornamental fishes (Table 1). Considering its indiscriminate use and easy availability, safe limits of astaxanthin are considered to be $100 \mathrm{mg} / \mathrm{kg}$ by the US FDA for salmonids, rainbow trout and crustaceans ${ }^{62}$. In addition, astaxanthin doubles up as a potent antioxidant to boost immune responses in crustaceans, specially shrimps ${ }^{63-65}$.

\section{Genetic manipulation as a strategy of colour enhancement}

Constant jeopardy of colour loss, need for technical expertise in carotenoid supplementation and escalating improbabilities arising due to dependent and independent variables, led to the development of genetic means of colour enhancement, which were backed by advantages of being stable and heritable. Inheritable traits were emphasized for developing colour patterns in ornamental fishes solely based on the findings on inheritable genes linked to varied colour patterns in guppies (Poecilia reticulata). Since Winge ${ }^{66}$ attempted to compose possibly the first genetic linkage map among vertebrates, fishes from family Poeciliidae have been a model for the study of evolution, ecology, behaviour, tumour genetics and genomics, but most importantly, for sex-linked inheritance of a variety of masculine ornamental traits important for sexual selection and adaptation in natural populations ${ }^{67-69}$. Extensive genetic research elucidated that guppy has an XY sex-determination system, wherein the Y-chromosome harbours male sex-determining locus in tight genetic linkage to masculine ornamental genes ${ }^{69}$. Interestingly, recombination rates in the swordtail (Xiphophorus spp.) do not show any sex-specific proclivity, unlike zebrafish ${ }^{70}$.

With advancements in transgenic technology, the fish became a good model for transgene induction in the mid1980 s owing to its easy husbandry practices and potential for fast growth. Although the first transgenic fish was produced in 1985 (ref. 71), initial research attempts suffered redundancy in real-time data due to non-availability of promoters from homologues species and laborious work involved in the analysis of classical reporter genes such as CAT (catecholamine transferase), $\beta$-galactosidase and luciferase. Successful demonstration of fluorescence reporter proteins, such as green fluorescent protein (GFP), enhanced green fluorescent protein (EGFP), and 
Table 1. Astaxanthin supplementation in ornamental fishes

\begin{tabular}{lcc}
\hline Fish species & Astaxanthin supplementation (mg/kg) & Reference \\
\hline Penaeus monodon (Tiger shrimp) & $50-100$ & 63 \\
Carasius auratus (Gold fish) & 45 & 89 \\
Hyphessobrycon callistus (Serpae tetra) & 40 & 90 \\
Colisa lalia (Dwarf gourami) & 100 & 91 \\
Cichlasoma citrenellum (Midas cichlid) & 160 & 92 \\
Premnas biaculeatus (Spinecheek anemonefish) & 214 & 93 \\
Amphiprion ocellaris (Common clownfish) & $80-160$ \\
\hline
\end{tabular}

subsequently, blue (BFP), cyan (CFP) and red, opened new horizons in live cell imaging for confirming transgenic technology in live embryos and cells without sacrificing the fish for fluorescence microscopy ${ }^{71}$. Transgenic status can now also be confirmed with immunohistochemistry using confocal microscopy and fluorescent in situ hybridization to narrow down cellular arrangements for induced colouration. Colourful as well as fluorescent varieties of zebrafish and medaka have been generated using this technology, adding luxurious hues over physiological colourations. One of the pioneering attempts was that using muscle-specific gene, mylz2, and a skinspecific gene, keratin 8 promoters for GFP and development of a transgenic zebrafish showing green fluorescence bright enough to be observed under daylight. Subsequent attempts also yielded fruitful results with red and yellow fluorescent proteins ${ }^{71-74}$. This became the most successful commercial application of transgenic technology, marketed under trade name of 'Glo Fish' after sufficient media stir regarding ANDi (the first transgenic primate), and Alba (the transgenic GFP rabbit $)^{75}$. With advancements in transgenics, use of CFPs like AmCyan1 (mutant version of the CFP, amFP486 having excitation spectra $458 \mathrm{~nm}$ and emission spectra $489 \mathrm{~nm}$ ) has been attempted for displaying a yellowgreen colour under normal daylight or white light, a brilliant green fluorescence under ultraviolet light and a cyan-like fluorescence under blue light (from a lightemitting diode) in marine medakas (Oryzias dancana), showing promising results and scope for further stu$\operatorname{dies}^{76,77}$. Various studies have expressed concern over the release of such transgenic fishes in public water bodies, foreseeing ecological orchestration that may result from such introductions ${ }^{78-80}$.

\section{Subcutaneous injection of pigments and dyeing as strategies for colour enhancement}

The booming ornamental fish trade gave way to many unethical practices of colour enhancement, foremost being painting, more commonly known as 'juicing, ${ }^{81,82}$. This practice started in the late 1970s with glassfish ( $\mathrm{Pa}$ rambassis ranga), whose glassy or transparent appearance presented a perfect canvas for subcutaneous injection of dyes to earn a better price ${ }^{83}$. Studies have shown that such subcutaneous injection of industrial synthetic dyes is traumatic to an extent that it may be fatal $^{83,84}$. Furthermore, the process of colour injection itself is gruesome, wherein numerous wounds are inflicted on tiny fish via needles on the dorsal and ventral musculature, making them immunocompromised ${ }^{82}$. Other methods of colour enhancement are dipping the fish in caustic dyes (cause sloughing-off of the natural pigmentation pattern), superimposing the intended colours on the fish body. These caustic dyes damage the first barrier of defence, i.e. skin, destroying lysozymes and other immunoreactive molecules thus making the fish susceptible to pathogen attack ${ }^{85}$. There have been enough protests to deter people from buying such painted fish, suggesting the need of a legislative ban to be imposed on such type of heinous techniques. However, conclusive action is awaited, keeping avenues open for moral and legal police to do their part.

\section{Conclusion}

Research on colour development and enhancement has traversed a long journey and future research may provide answers regarding the effects of abiotic parameters in governing colouration. Bio-reporter genes may be instrumental to indicate a shift in the colour in response to the desirable titre of the chemical or concerned pollutant. Caution should be exercised during use of these techniques following ethical and legal guidelines, ensuring their sustainability. Strategies for inducing selective fertility in transgenic fishes (on/off strategy) and other reproductive containment techniques are essential to prevent unwanted integration of the transgene into nontarget organisms ${ }^{86}$.

Insights from research on the role of micronutrients (calcium, iron and zinc; enhancing the plumage colour pattern in zebra finches) provided another avenue for a study ${ }^{87}$ warranting attention of fish biologists on their potency in augmenting general health status and disease resistance $^{88}$. However, their roles in colour enhancement still remain unexplored. Future research must ensure total abstinence from unethical painting/juicing techniques, and should be directed towards creating a mass awareness against the ill-effects of such heinous practices on fish health. Menaces like ornamental fish colour pollution 


\section{REVIEW ARTICLES}

should be discouraged at its advent to safeguard the interests of stakeholders and native biodiversity. There should be enough considerations to protect the feral exit of such colour-enhanced fishes into the wild, which might produce risks of unwanted inheritance of colour patterns and problems of identity crisis among conspecifics. Although the nature of inheritance of colouration and pigmentation remains poorly studied in fishes, future techniques, if harnessed with caution, are bound to bring a global 'rainbow revolution' to the ornamental fish industry.

1. Jayalal, L. and Ramachandran, A., Export trend of Indian ornamental fish industry. Agric. Biol. J. N. Am., 2012, 3, 439-451.

2. Mendoza, R., Luna, S. and Aguilera, C., Risk assessment of the ornamental fish trade in Mexico: analysis of freshwater species and effectiveness of the fisk (fish invasiveness screening kit). Biol. Invas., 2015, 17, 3491-3502.

3. Green, E., International trade in marine aquarium species: using the global marine aquarium database. In Marine Ornamental Species: Collection, Culture and Conservation (eds Cato, J. C. and Brown, J. L.), Wiley, Iowa State Press, 2003, pp. 29-48.

4. Dee, L. E., Horii, S. S. and Thornhill, D. J., Conservation and management of ornamental coral reef wildlife: successes, shortcomings, and future directions. Biol. Conserv., 2014, 169, 225 237.

5. Leal, M. C., Vaz, M. C. M., Puga, J., Rocha, R. J. M., Brown, C., Rosa, R. and Calado, R., Marine ornamental fish imports in the European Union: an economic perspective. Fish Fish., 2016, 17, 459-468.

6. Sharp, S., Death by dyeing: About.Com (retrieved 19 May 2006).

7. Beyer, J., Bechmann, R., Taban, I., Aas, E., Reichert, W., Seljeskog, E. and Sanni, S., Biomarker measurements in long term exposures of a model fish to produced water components (PAHS and alkylphenols). Akvamiljø, Report AM-01/007, 2007, pp. 128.

8. Cal, L., Suarez-Bregua, P., Moran, P., Cerdá-Reverter, J. M. and Rotllant, J., Fish pigmentation. A key issue for the sustainable development of fish farming. In Emerging Issues in Fish Larvae Research (ed. Yufera, M.), Springer Nature, Switzerland, pp. 229 252.

9. Sköld, H. N., Aspengren, S., Cheney, K. L. and Wallin, M., Fish chromatophores - from molecular motors to animal behavior. In International Review of Cell and Molecular Biology, Elsevier, 2016, vol. 321, pp. 171-219.

10. Ceinos, R. M., Guillot, R., Kelsh, R. N., Cerdá-Reverter, J. M. and Rotllant, J., Pigment patterns in adult fish result from superimposition of two largely independent pigmentation mechanisms. Pigm. Cell Melanoma Res., 2015, 28, 196-209.

11. Kelsh, R. N., Sosa, K. C., Owen, J. P. and Yates, C. A., Zebrafish adult pigment stem cells are multipotent and form pigment cells by a progressive fate restriction process. BioEssays, 2017, 39.

12. Fujii, R., Correlation between fine structure and activity in fish melanophore. In Structure and Control of the Melanocyte (eds Della Porta, G. and Mühlbock, O.), Springer, 1966, pp. 114-123.

13. Fujii, R., Goda, M. and Oshima, N., Mechanism by which an elevation of extracellular glucide concentration induces pigment aggregation in medaka melanophores. Micros. Res. Tech., 2002, $\mathbf{5 8}, 514-522$.

14. Krauss, J., Frohnhöfer, H. G., Walderich, B., Maischein, H.-M., Weiler, C., Irion, U. and Nüsslein-Volhard, C., Endothelin signalling in iridophore development and stripe pattern formation of zebrafish. Biol. Open, 2014, 3, 503-509; https://bio.biologists.org/ content $/ 3 / 6 / 503$.
15. Yamaguchi, M., Yoshimoto, E. and Kondo, S., Pattern regulation in the stripe of zebrafish suggests an underlying dynamic and autonomous mechanism. Proc. Natl. Acad. Sci. USA, 2007, 104, 4790-4793.

16. Sugimoto, M., Morphological color changes in fish: regulation of pigment cell density and morphology. Microsc. Res. Tech., 2002, 58, 496-503.

17. Cheney, K. L., Grutter, A. S. and Marshall, N. J., Facultative mimicry: cues for colour change and colour accuracy in a coral reef fish. Proc. R. Soc. London, Ser. B, 2008, 275, 117-122.

18. Kelley, J. L., Phillips, B., Cummins, G. H. and Shand, J., Changes in the visual environment affect colour signal brightness and shoaling behaviour in a freshwater fish. Anim. Behav., 2012, 83, 783-791.

19. Nilsson Sköld, H., Aspengren, S. and Wallin, M., Rapid color change in fish and amphibians - function, regulation, and emerging applications. Pigm. Cell Melanoma Res., 2013, 26, 29-38.

20. Svensson, P. A. and Wong, B., Carotenoid-based signals in behavioural ecology: a review. Behaviour, 2011, 148, 131-189.

21. Chatzifotis, S., Pavlidis, M., Jimeno, C. D., Vardanis, G., Sterioti, A. and Divanach, P., The effect of different carotenoid sources on skin coloration of cultured red porgy (Pagrus pagrus). Aquacult. Res., 2005, 36, 1517-1525.

22. Kuhn, R. and Lederer, E., Decomposition of carotene into its components. The growth vitamin. Part 1. Ber. Deutsch. Chem. Gesellsch., 1931, 64, 1349-1357.

23. Maoka, T., Carotenoids in marine animals. Mar. Drugs, 2011, 9, 278-293.

24. Goodwin, T. W., Carotenoids in fish. In The Biochemistry of Fish, Biochemical Society Symposia, USA, 1951.

25. Doolan, B. J., Allan, G. L., Booth, M. A. and Jones, P. L., Effect of carotenoids and background colour on the skin pigmentation of australian snapper Pagrus auratus (Bloch \& Schneider, 1801). Aquacult. Res., 2008, 39, 1423-1433.

26. Ha, B.-S., Kang, D.-S., Kim, J.-H., Choi, O.-S. and Ryu, H.-Y., Metabolism of dietary carotenoids and effects to improve the body color of cultured flounder and red sea bream. Kor. J. Fish. Aquat. Sci., 1993, 26, 91-101.

27. Yasir, I. and Qin, J. G., Effect of dietary carotenoids on skin color and pigments of false clownfish, Amphiprion ocellaris, Cuvier. $J$. World Aquacult. Soc., 2010, 41, 308-318.

28. Hata, M., Carotenoid pigments in goldfish - IV. Carotenoid metabolism. Bull. Jpn. Soc. Sci. Fish., 1972, 38, 331-338.

29. Rahman, M. M., Khosravi, S., Chang, K. H. and Lee, S.-M., Effects of dietary inclusion of astaxanthin on growth, muscle pigmentation and antioxidant capacity of juvenile rainbow trout (Oncorhynchus mykiss). Prev. Nutr. Food Sci., 2016, 21, 281.

30. Amaya, E. and Nickell, D., Using feed to enhance the color quality of fish and crustaceans. In Feed and Feeding Practices in Aquaculture (ed. Allan Davis, D.), Elsevier, 2015, pp. 269-298.

31. Bjerkeng, B. and Berge, G., Apparent digestibility coefficients and accumulation of astaxanthin e/z isomers in Atlantic salmon (Salmo salar 1.) and Atlantic halibut (Hippoglossus hippoglossus 1.). Comp. Biochem. Physiol. Part B, 2000, 127, 423-432.

32. Brown, A. C., Leonard, H. M., McGraw, K. J. and Clotfelter, E. D., Maternal effects of carotenoid supplementation in an ornamented cichlid fish. Funct. Ecol., 2014, 28, 612-620.

33. Sefc, K. M., Brown, A. C. and Clotfelter, E. D., Carotenoid-based coloration in cichlid fishes. Comp. Biochem. Physiol. Part A, 2014, 173, 42-51.

34. McGraw, K. J. and Ardia, D. R., Carotenoids, immunocompetence, and the information content of sexual colors: an experimental test. Am. Nat., 2003, 162, 704-712.

35. Lozano, G. A., Carotenoids, parasites, and sexual selection. Oikos, 1994, 70, 309-311.

36. Andersson, S., Pryke, S. R., Örnborg, J., Lawes, M. J. and Andersson, M., Multiple receivers, multiple ornaments, and a trade-off 
between agonistic and epigamic signaling in a widowbird. Am. Nat., 2002, 160, 683-691.

37. Fitzpatrick, S., Colour schemes for birds: structural coloration and signals of quality in feathers. Ann. Zool. Fenn., 1998, 35, 67-77.

38. Cotton, S., Fowler, K. and Pomiankowski, A., Do sexual ornaments demonstrate heightened condition-dependent expression as predicted by the handicap hypothesis? Proc. R. Soc. London, Ser. $B, 2004,271,771$.

39. de Carvalho, C. C. and Caramujo, M. J., Carotenoids in aquatic ecosystems and aquaculture: a colorful business with implications for human health. Front. Mar. Sci., 2017, 4, 93.

40. Boonyaratpalin, M. and Lovell, R., Diet preparation for aquarium fishes. Aquaculture, 1977, 12, 53-62.

41. Boonyaratpalin, M. and Phromkunthong, W., Effects of carotenoid pigments from different sources on colour changes of fancy carp, Cyprinus carpio Linn. J. Sci. Technol., 1986, 8, 11-20.

42. Ako, H., Tamaru, C. S., Asano, L., Yuen, B. and Yamamoto, M., Achieving natural coloration in fish under culture. US-Japan Cooperative Program in Natural Resources Technical Report, No. 28, 2000, pp. 1-4.

43. Güroy, B., Şahin, İ., Mantoğlu, S. and Kayalı, S., Spirulina as a natural carotenoid source on growth, pigmentation and reproductive performance of yellow tail cichlid Pseudotropheus acei. Aquacult. Int., 2012, 20, 869-878.

44. Somanath, B. and Jasmin, K. J., Hibiscus petals and spirulina supplemented diet induced carotenoid changes in freshwater gold fish Carassius auratus. Int. J. Pure Appl. Zool., 2013, 4, 352-362.

45. Becker, W., Microalgae for aquaculture: the nutritional value of microalgae for aquaculture. In Handbook of Microalgal Culture: Biotechnology and Applied Phycology (ed. Richmond, A.), Blackwell, 2004, pp. 380-391.

46. Gupta, S., Jha, A., Pal, A. and Venkateshwarlu, G., Use of natura carotenoids for pigmentation in fishes. Indian J. Nat. Prod. Resour., 2014, 6(1), 46-49.

47. Valente, L. M. et al., Carotenoid deposition, flesh quality and immunological response of Nile tilapia fed increasing levels of imta-cultivated Ulva spp. J. Appl. Phycol., 2016, 28, 691-701.

48. Neamtu, G. and Simpson, K. L., Utilization of Adonis aestivalis as a dietary pigment source for rainbow trout Salmo gairdneri. Nippon Suisan Gakkaishi, 1990, 56, 783-788.

49. Shah, S. N. M., Shi-Lin, T., Gong, Z.-H. and Arisha, M. H., Studies on metabolism of capsanthin and its regulation under different conditions in pepper fruits (Capsicum spp.). Annu. Res. Rev. Biol., 2014, 4, 1106.

50. Wassef, E. A., Chatzifotis, S., Sakr, E. M. and Saleh, N. E., Effect of two natural carotenoid sources in diets for gilthead seabream, Sparus aurata, on growth and skin coloration. J. Appl. Aquacult., 2010, 22, 216-229.

51. Sinha, A. and Asimi, O. A., China rose (Hibiscus rosasinensis) petals: a potent natural carotenoid source for goldfish (Carassius auratus 1.). Aquacult. Res., 2007, 38, 1123-1128.

52. Ramamoorthy, K., Bhuvaneswari, S., Sankar, G. and Sakkaravarthi, K., Proximate composition and carotenoid content of natural carotenoid sources and its colour enhancement on marine ornamental fish Amphiprion ocellaris (Cuveir 1880). World J. Fish Mar. Sci., 2010, 2, 545-550.

53. Sujatha, B. J. S., Shalin, J. J. and Palavesam, A., Influence of four ornamental flowers on the growth and colouration of orange sword tail Chicilidae fish (Xiphophorus hellerei, Heckel, 1940). Int. J. Biol. Med. Res., 2011, 2(3), 621-626.

54. Jha, G. N., Dar, B. A., Jha, T., Sarma, D. and Qureshi, T., Effect of spirulina and apple peel meal on growth performance, body composition and total carotenoids of snow trout (Schizothorax richardsonii). Indian J. Anim. Nutr., 2013, 30, 404-409.

55. Jagadeesh, T., Murthy, H. S., Surendranath, S., Panikkar, P., Manjappa, N. and Mahesh, V., Effects of supplementation of marigold (Tagetes erecta) oleoresin on growth, survival and pigmentation of rosy barb, Puntius conchonius (Hamilton). Int. Q. J. Life Sci., 2015, 10(3), 1431-1435.

56. García-Chavarría, M. and Lara-Flores, M., The use of carotenoid in aquaculture. Res. J. Fish. Hydrobiol., 2013, 8, 38-49.

57. Arvanitoyannis, I. S. and Kassaveti, A., Fish industry waste: treatments, environmental impacts, current and potential uses. Int. J. Food Sci. Technol., 2008, 43, 726-745.

58. Huggins, K. A., Navara, K. J., Mendonça, M. T. and Hill, G. E., Detrimental effects of carotenoid pigments: the dark side of bright coloration. Naturwissenschaften, 2010, 97, 637-644; doi:10.1007/ s00114-010-0679-6.

59. Fox, H. M. and Vevers, G., The Nature of Animal Colours, Macmillan, New York, USA, 1960.

60. Pattanaik, S. S., Sawant, P. B., Xavier, K. M., Dube, K., Srivastava, P. P., Dhanabalan, V. and Chadha, N. K., Characterization of carotenoprotein from different shrimp shell waste for possible use as supplementary nutritive feed ingredient in animal diets. Aquaculture, 2020, 515, 734594; https://doi.org/10.1016/j.aquaculture. 2019.734594.

61. Barbosa, M., Morais, R. and Choubert, G., Effect of carotenoid source and dietary lipid content on blood astaxanthin concentration in rainbow trout (Oncorhynchus mykiss). Aquaculture, 1999, 176, 331-341.

62. Tetens, I. and Poulsen, M., Scientific opinion on the safety of astaxanthin-rich ingredients (astareal a1010 and astareal 110) as novel food ingredients. EFSA J., 2014, 12(7), 3757.

63. Chien, Y.-H., Pan, C.-H. and Hunter, B., The resistance to physical stresses by Penaeus monodon juveniles fed diets supplemented with astaxanthin. Aquaculture, 2003, 216, 177-191.

64. Chien, Y.-H. and Shiau, W.-C., The effects of dietary supplementation of algae and synthetic astaxanthin on body astaxanthin, survival, growth, and low dissolved oxygen stress resistance of kuruma prawn, Marsupenaeus japonicus Bate. J. Exp. Mar. Biol. Ecol., 2005, 318, 201-211.

65. Niu, J., Tian, L. X., Liu, Y. J., Yang, H. J., Ye, C. X., Gao, W. and Mai, K. S., Effect of dietary astaxanthin on growth, survival, and stress tolerance of postlarval shrimp, Litopenaeus vannamei. J. World Aquacul. Soc., 2009, 40, 795-802.

66. Winge, Ö., The location of eighteen genes in Lebistes reticulatus. J. Genet., 1927, 18, 1-43.

67. Crispo, E., Bentzen, P., Reznick, D. N., Kinnison, M. T. and Hendry, A. P., The relative influence of natural selection and geography on gene flow in guppies. Mol. Ecol., 2006, 15, 49-62.

68. Zajitschek, S. R. and Brooks, R. C., Distinguishing the effects of familiarity, relatedness, and color pattern rarity on attractiveness and measuring their effects on sexual selection in guppies (Poecilia reticulata). Am. Nat., 2008, 172, 843-854.

69. Tripathi, N., Hoffmann, M., Willing, E.-M., Lanz, C., Weigel, D. and Dreyer, C., Genetic linkage map of the guppy, Poecilia reticulata and quantitative trait loci analysis of male size and colour variation. Proc. R. Soc. London, Ser. B, 2009, 276, 2195-2208.

70. Khoo, G. et al., Genetic linkage maps of the guppy (Poecilia reticulata): assignment of rapid markers to multipoint linkage groups. Mar. Biotechnol., 2003, 5, 279-293.

71. Zhu, Z., He, L. and Chen, S., Novel gene transfer into the fertilized eggs of gold fish (Carassius auratus 1. 1758). J. Appl. Ichthyol., 1985, 1, 31-34.

72. Gong, Z., Wan, H., Tay, T. L., Wang, H., Chen, M. and Yan, T., Development of transgenic fish for ornamental and bioreactor by strong expression of fluorescent proteins in the skeletal muscle. Biochem. Biophys. Res. Commun., 2003, 308(1), 58-63.

73. Wan, H., He, J., Ju, B., Yan, T., Lam, T. J. and Gong, Z., Generation of two-color transgenic zebrafish using the green and red fluorescent protein reporter genes $g f p$ and $r f p$. Mar. Biotechnol., 2002, 4, 146-154.

74. Gong, Z., Ju, B. and Wan, H., Green fluorescent protein (gfp) transgenic fish and their applications. Genetica, 2001, 111, 213-225. 


\section{REVIEW ARTICLES}

75. Stewart Jr, C. N., Go with the glow: fluorescent proteins to light transgenic organisms. Trends Biotechnol., 2006, 24, 155-162.

76. Vu, N. T., Cho, Y. S., Lee, S. Y., Kim, D. S. and Nam, Y. K., A cyan fluorescent protein gene ( $c f p$ )-transgenic marine medaka Oryzias dancena with potential ornamental applications. Fish. Aquat. Sci., 2014, 17, 479-486.

77. Lee, O., Green, J. M. and Tyler, C. R., Transgenic fish systems and their application in ecotoxicology. Crit. Rev. Toxicol., 2015, 45, 124-141.

78. Maclean, N. and Laight, R. J., Transgenic fish: an evaluation of benefits and risks. Fish Fish., 2000, 1, 146-172.

79. Devlin, R. H., Sundström, L. F. and Muir, W. M., Interface of biotechnology and ecology for environmental risk assessments of transgenic fish. Trends Biotechnol., 2006, 24, 89-97.

80. Piferrer, F., Beaumont, A., Falguière, J.-C., Flajšhans, M., Haffray, P. and Colombo, L., Polyploid fish and shellfish: production, biology and applications to aquaculture for performance improvement and genetic containment. Aquaculture, 2009, 293, 125-156.

81. Ng, P. K. and Tan, H., Freshwater fishes of Southeast Asia: potential for the aquarium fish trade and conservation issues. Aquarium Sci. Conserv., 1997, 1, 79-90.

82. Eşanu, V. O., Gavriloaie, C., Oroian, I. G. and Burny, P., Few remarks regarding some unnatural aquarium fish breeds and improper fish maintenance. Aquacult. Aquarium, Conserv. Legis., $2015,8,236-243$

83. Eşanu, V. O., Gavriloaie, C., Oroian, I. G. and Burny, P., Some considerations concerning the artificially colored aquarium fish trade. Aquacult. Aquarium, Conserv. Legis., 2015, 8, 116121.

84. Al-Sabti, K., Chlorotriazine reactive azo red 120 textile dye induces micronuclei in fish. Ecotoxicol. Environ. Safety, 2000, 47, $149-155$.

85. Ángeles Esteban, M., An overview of the immunological defenses in fish skin. ISRN Immunol., 2012, 1-29.

86. Devlin, R. H. and Donaldson, E. M., Containment of genetically altered fish with emphasis on salmonids. In Transgenic Fish (eds Hew, C. L. and Fletcher, G. L.), World Scientific, Singapore, 1992, pp. 229-265.
87. McGraw, K. J., Dietary mineral content influences the expression of melanin-based ornamental coloration. Behav. Ecol., 2006, 18, 137-142.

88. Lall, S. P., The minerals. In Fish Nutrition (Third Edition) (ed. Hardy, R.), Elsevier Academic Press, 2002, pp. 259-308.

89. Rema, P. and Gouveia, L., Effect of various sources of carotenoids on survival and growth of goldfish (Carassius auratus) larvae and juveniles. J. Anim. Vetern. Adv., 2005, 4(7), 654-658.

90. Wang, Y.-J., Chien, Y.-H. and Pan, C.-H., Effects of dietary supplementation of carotenoids on survival, growth, pigmentation, and antioxidant capacity of characins, Hyphessobrycon callistus. Aquaculture, 2006, 261, 641-648.

91. Baron, M., Davies, S., Alexander, L., Snellgrove, D. and Sloman, K., The effect of dietary pigments on the coloration and behaviour of flame-red dwarf gourami, Colisa lalia. Anim. Behav., 2008, 75, 1041-1051.

92. Pan, C. H. and Chien, Y. H., Effects of dietary supplementation of alga Haematococcus pluvialis (Flotow), synthetic astaxanthin and $\beta$-carotene on survival, growth, and pigment distribution of red devil, Cichlasoma citrinellum (Günther). Aquacul. Res., 2009, 40, 871-879.

93. Ho, A. L., Orlando Bertran, N. M. and Lin, J., Dietary esterified astaxanthin concentration effect on dermal coloration and chromatophore physiology in spinecheek anemonefish, Premnas biaculeatus. J. World Aquacult. Soc., 2013, 44, 76-85.

94. Ho, A. L., O'Shea, S. K. and Pomeroy, H. F., Dietary esterified astaxanthin effects on color, carotenoid concentrations, and compositions of clown anemonefish, Amphiprion ocellaris, skin. Aquacult. Int., 2013, 21, 361-374.

95. Diler, I. and Dilek, K., Significance of pigmentation and use in aquaculture. Turk. J. Fish. Aquat. Sci., 2002, 2, 97-99.

Received 8 June 2019; revised accepted 23 July 2020

doi: $10.18520 / \mathrm{cs} / \mathrm{v} 119 / \mathrm{i} 7 / 1093-1100$ 